\title{
PRK Enhancement for Residual Refractive Error After Primary PRK: A Retrospective Study
}

\author{
Majid Moshirfar (D) - Alex Villarreal · Andrew C. Thomson • \\ William B. West Jr · Shannon E. McCabe · Eduardo Quinonez Zanabria • \\ Derrick B. Graham • Yasmyne C. Ronquillo • Phillip C. Hoopes Sr
}

Received: November 23, 2020 / Accepted: January 9, 2021 / Published online: January 30, 2021

(C) The Author(s) 2021

\section{ABSTRACT}

Introduction: The efficacy and safety of photorefractive keratectomy (PRK) has been well documented, but outcomes of PRK enhancement following PRK remain understudied. This

M. Moshirfar ( $₫)$. S. E. McCabe · Y. C. Ronquillo · P. C. Hoopes $\mathrm{Sr}$

Hoopes Vision Research Center, Hoopes Vision, Draper, UT, USA

e-mail: cornea2020@me.com

\section{Moshirfar}

Department of Ophthalmology and Visual Sciences, John A. Moran Eye Center, University of Utah

School of Medicine, Salt Lake City, UT, USA

M. Moshirfar

Utah Lions Eye Bank, Murray, UT, USA

A. Villarreal · A. C. Thomson

McGovern Medical School, The University of Texas

Health Science Center, Houston, TX, USA

W. B. West Jr

University of Utah School of Medicine, Salt Lake

City, UT, USA

S. E. McCabe

Mission Hills Eye Center, Pleasant Hill, CA, USA

E. Quinonez Zanabria

University of Arizona College of Medicine, Tucson, AZ, USA

D. B. Graham

Texas Tech University Health Sciences Center

School of Medicine, Lubbock, TX, USA study aimed to evaluate the safety, efficacy, and predictability of PRK enhancement in patients with residual refractive error after primary PRK and compare these results to prior studies as well as Food and Drug Administration (FDA) safety and efficacy clinical endpoints.

Methods: This non-randomized, retrospective chart analysis included eyes with a history of PRK that underwent PRK enhancement at a single center. Post-enhancement data were documented at 3-month and 1-year visits. Patient characteristics between the study group and a control group who underwent primary PRK only were compared. Safety and efficacy measures included change in uncorrected distance visual acuity (UDVA), change in corrected distance visual acuity (CDVA), manifest refraction spherical equivalent (MRSE), amount of induced astigmatism, and presence of serious adverse events.

Results: A total of 188 eyes from 141 patients were included. When compared to the control group, women underwent PRK enhancement at a higher rate than men $(P=0.004)$. The group undergoing PRK enhancement had a higher sphere $(P=0.013)$ and spherical equivalent $(P=0.004)$ than the control group at the time of primary PRK. MRSE was reduced to $-0.97 \pm 0.72 \mathrm{D}(-2.25$ to $+2.13 \mathrm{D})$ from preenhancement values of $-0.98 \pm 0.66 \mathrm{D}$ $(-2.75$ to $+1.75 \mathrm{D})$ and stable over 12 -month visits with $86 \%$ and $98 \%$ of eyes within $\pm 0.50 \mathrm{D}$ and $\pm 1.00 \mathrm{D}$ of target, 
respectively. UDVA of $20 / 20$ or better was achieved in $75 \%$ of eyes. The UDVA of $75 \%$ of eyes remained the same or improved by 1 or more Snellen lines compared with pre-enhancement CDVA.

Conclusion: Our results demonstrate that, when compared with previous studies, modern PRK enhancement after PRK has improved visual acuity and refractive outcomes. Though PRK enhancement is not an FDA approved procedure, we show that it meets or exceeds the FDA criteria for the correction of refractive error.

Keywords: Enhancement; Photorefractive keratectomy; PRK enhancement

\section{Key Summary Points}

\section{Why carry out this study?}

Within the last 25 years, there has been a lack of research published pertaining to the visual outcomes of patients receiving photorefractive keratectomy (PRK) enhancement after primary PRK. The study aims to examine the safety, efficacy, and predictability of PRK enhancement following primary PRK.

The study asked, "What are the visual outcomes of patients undergoing PRK enhancement after primary PRK?"

\section{What was learned from the study?}

When compared to the published studies, our results show that modern PRK enhancement after primary PRK has improved refractive outcomes and visual acuity.

PRK enhancement following PRK is not FDA approved; however, our study shows that it meets or exceeds the FDA safety, efficacy, and refractive predictability requirements for refractive error correction.

\section{DIGITAL FEATURES}

This article is published with digital features, including a summary slide, to facilitate understanding of the article. To view digital features for this article go to https://doi.org/10.6084/ m9.figshare.13475910.

\section{INTRODUCTION}

The most common cause of visual impairment worldwide is uncorrected refractive error [1]. Fortunately, patients now have a multitude of options when seeking improvement in visual acuity, including several permanent and convenient solutions. Corneal refractive surgical procedures have become some of the most commonly performed ophthalmologic surgeries in the world with many new options and techniques arising from the exploration of laser technology [2]. Conventional refractive surgery has largely been replaced by the implementation of wavefront technology, with patients benefiting from improvements in the efficacy and safety of refractive procedures [3]. While the technology has evolved tremendously since the advent of laser-assisted in situ keratomileusis (LASIK), retreatment surgery is sometimes necessary in order to maximize visual outcomes [4]. The two most common refractive surgeries for the correction of refractive error and astigmatism are photorefractive keratectomy (PRK) and LASIK.

PRK is less common than LASIK as a result of the slower recovery time and concern for increased postoperative pain but remains an option for patients who do not want incisional surgery or have contraindications to LASIK such as thin corneas, increased risk of corneal ectasia, and epithelial basement membrane dystrophy, among others [3, 5]. Overcorrection, undercorrection, and regression are potential complications seen after PRK. The management of these residual and recurring refractive errors depends on the type of refractive error, corneal thickness, and corneal haze. Retreatment options include LASIK, repeat PRK, phototherapeutic keratectomy (PTK), and possibly even collagen cross-linking [6, 7]. While PRK enhancement for 
residual refractive error after PRK has been studied, little investigation has occurred over the last 2 decades regarding the safety and outcomes of PRK enhancement after PRK, despite significant advances in techniques and technologies [8-12].

The objective of this study is to analyze the visual outcomes, safety, efficacy, and predictability of enhancement with PRK after primary PRK and compare results with studies published over the last 25 years as well as Food and Drug Administration (FDA) criteria.

\section{METHODS}

This is a retrospective analysis of patients who underwent wavefront-optimized PRK enhancement after primary PRK refractive surgery at Hoopes Vision between February 2014 and December 2019. The PRK enhancement surgeries were performed by two surgeons at Hoopes Vision. A control group was obtained from a Hoopes Vision database consisting of de-identified patient data between February 2014 and December 2019. The patients included in the control group did not receive PRK enhancement after primary PRK, with only one primary surgeon. Our primary reason for retreatment was patient dissatisfaction attributable to residual refractive error after primary PRK. A refractive screening was completed, and patients with preexisting ocular pathologies or abnormal topographies were excluded from the study. These pathologies included age-related macular degeneration, keratoconus, prior retinal tears, and other retinal or corneal pathology that could affect visual acuity. Patients with prior enhancement procedures were also excluded. De-identified data of included patients were used for the analysis. Patients gave informed consent for all procedures and the use of deidentified clinical data in research. The study and consent procedure were approved by the Hoopes Vision Ethics Committee and BRANY Institutional Review Board, and also adhered to the tenets of the Declaration of Helsinki.

Post-enhancement data were then documented at the 3-month and 1-year post-enhancement visits. Outcomes were analyzed according to the Standard 9 Graphs for reporting safety, efficacy, stability, and predictability of refractive surgery [13]. Patient characteristics between the control and enhancement groups were analyzed using a chi-square test for gender and surgical eyes and a $t$ test for age, UDVA (uncorrected distance visual acuity), CDVA (corrected distance visual acuity), pre-enhancement sphere, pre-enhancement cylinder, spherical equivalent, pachymetry, and preoperative keratometry values. Statistical significance was defined as a $P$ value of 0.05 or less.

For the literature review, the keywords used were "PRK", "photorefractive keratectomy", "enhanced", "retreatment", and "outcomes". The databases searched were PubMed, Cochrane Library, ClinicalKey, Medline, and EMBASE. The review yielded 46 articles, seven of which were used. The rest were discarded because of either not being relevant to PRK enhancement or having a sample size of less than four eyes.

\section{PRK Retreatment}

The retreatment surgical procedure was done using 18\% alcohol for epithelial debridement followed by use of the WaveLight EX500 excimer laser system (Alcon Laboratories, Inc.) with ablation zone of $6.5 \mathrm{~mm}$ and transitional zone to $9.0 \mathrm{~mm}$. Mitomycin C $0.02 \%$ was applied for $20 \mathrm{~s}$ if ablation depth exceeded 65 microns. An Acuvue Oasys (Johnson \& Johnson Vision Care, Inc.) $8.4 \mathrm{~mm}$ base curve bandage contact lens was placed and maintained for 1 week postoperatively. The postoperative treatment protocol included moxifloxacin $0.5 \%$ four times a day for 1 week. Patients were instructed to apply prednisolone acetate $1 \%$ four times daily for 1 month. One month following surgery, they were switched to fluorometholone $0.1 \%$ four times daily, then this was tapered and discontinued at 8 weeks following surgery.

\section{RESULTS}

A total of 2995 eyes underwent primary PRK in Hoopes Vision between 2014 and 2019. Out of the 2995 eyes, 188 required enhancement, with an enhancement rate of $6 \%$. Our study included 
188 eyes from 141 patients undergoing PRK enhancement after primary PRK with the average time between procedures being $60 \pm 46$ months (Table 1 ). The study consisted of 172 myopic, 9 mixed astigmatic, and 7 hyperopic eyes. Table 1 shows how the preoperative and demographic characteristics of our study group compare to the control group, allowing us to identify possible risk factors for increased enhancement rate. The age at the time of the primary refractive surgery was not significantly different between the eyes requiring enhancement and the control group $(P=0.200)$. Women underwent PRK enhancement at a higher rate than men when compared to the control group who underwent primary PRK alone $(P=0.004)$. Both the original preoperative sphere $(P=0.013)$ and spherical equivalent $(P=0.004)$ were higher in the group undergoing PRK enhancement than the control group (Table 1). A chi-square test showed no significant difference in surgical eyes between our control and enhancement groups with a $P$ value of 0.195 . No other measured factors including CDVA, diopters of cylinder, pachymetry, and keratometry values showed a statistically significant difference between the enhancement group and the control group (Table 1). Twenty eyes experienced complications or had other findings after PRK enhancement. Haze was noted in 11 eyes and epithelial injection in two eyes, which all resolved. Endothelial pigment, corneal ulcer, corneal abrasion, dry eye, corneal scarring, chalazion, and neovascularization were other findings that either resolved or did not affect final vision in the affected eyes.

\section{Efficacy}

Prior to enhancement (ENH), $4 \%$ of eyes had a UDVA of $20 / 20$ or better, and $56 \%$ of eyes had a UDVA of $20 / 40$ or better, while $99 \%$ of eyes had a CDVA of $20 / 20$ or better and $100 \%$ of eyes had a CDVA of $20 / 40$ or better. At the 3-month postENH visit, $85 \%$ of eyes had a UDVA of $20 / 20$ or better, and $99 \%$ of eyes had a UDVA of $20 / 40$ or better (Fig. 1-I). At the 12-month retreatment assessment, $75 \%$ of eyes had a UDVA of $20 / 20$ or better, and $99 \%$ of eyes had a UDVA of 20/40 or better (Fig. 1-I). The efficacy was 1.10 at the 3 -month visits and 1.27 at the 12 -month visits. This data exceeds the FDA target criteria of a minimum of $85 \%$ of eyes achieving UDVA of $20 / 40$ or better for eyes with CDVA of $20 / 20$ or better preoperatively [14-16].

\section{Safety}

The UDVA after ENH was the same or better than the pre-enhancement CDVA in $84 \%$ of eyes, and the UDVA after ENH was within one line of the pre-enhancement CDVA in 95\% of eyes at the 3-month post-enhancement visit (Fig. 1-II). At the 12-month follow-up, $75 \%$ of eyes had a post-enhancement UDVA equal to or better than the CDVA before enhancement, while $91 \%$ of eyes had a UDVA within one line of CDVA (Fig. 1-II). The retreatment CDVA at the 12-month visit showed a loss of two or more lines in less than $1 \%$ of eyes with a patient developing a corneal ulcer in one eye (Fig. 1-III). The safety index was 0.89 at the 3 -month visits and 0.96 at the 12 -month visits. The FDA primary safety target criteria include a less than $5 \%$ rate of eyes with loss of two or more lines of CDVA, which our data meets at both the 3-month and 12-month follow-up visits with a loss of two or more lines in only less than $1 \%$ of eyes at both time points [9]. The safety criteria also includes a less than $1 \%$ rate of eyes with preoperative CDVA of $20 / 20$ or better with a postoperative CDVA worse than 20/40, which our data also meets with only a single eye out of 188 with an initial CDVA of 20/20 that developed a corneal ulcer leading to a CDVA of 20/50 at the 3-month mark and a CDVA of 20/40 at the 12-month mark [16].

\section{Predictability}

The average attempted refractive treatment for sphere was $-0.91 \mathrm{D}$ and $+1.01 \mathrm{D}$. The average attempted refractive treatment for cylinder was $-0.59 \mathrm{D}$. At the 3-month post-ENH assessment, the percentage of eyes that were within $\pm 0.50 \mathrm{D}$ and $\pm 1.00 \mathrm{D}$ of the intended target was $88 \%$ and $98 \%$, respectively. At the 
Table 1 Patient demographics

\begin{tabular}{|c|c|c|c|}
\hline Preoperative characteristics & PRK control $(n=399)$ & PRK enhancements $(n=188)$ & $P$ value \\
\hline \multicolumn{4}{|l|}{ Age (years) } \\
\hline Mean $\pm S D$ & $32.5 \pm 7.0$ & $34.86 \pm 9.39$ & 0.200 \\
\hline Range & 18 to 53 & 19 to 55 & \\
\hline \multicolumn{4}{|l|}{ Sex, no. (\%) } \\
\hline Male & $138(66 \%)$ & $71(50 \%)$ & 0.004 \\
\hline Female & $72(34 \%)$ & $70(50 \%)$ & \\
\hline \multicolumn{4}{|l|}{ Surgical eye, no. (\%) } \\
\hline Right & $200(50 \%)$ & $105(56 \%)$ & 0.195 \\
\hline Left & $199(50 \%)$ & $83(44 \%)$ & \\
\hline \multicolumn{4}{|l|}{ CDVA (logMAR) } \\
\hline Mean & 0.00 & 0.00 & 0.557 \\
\hline \multicolumn{4}{|l|}{ Sphere (D) } \\
\hline Mean $\pm S D$ & $-3.21 \pm 1.81$ & $-3.69 \pm 2.27$ & 0.013 \\
\hline Range & -8.75 to +1.25 & -8.75 to +2.25 & \\
\hline \multicolumn{4}{|l|}{ Cylinder (D) } \\
\hline Mean $\pm S D$ & $-0.92 \pm 0.92$ & $-1.09 \pm 1.02$ & 0.058 \\
\hline Range & -6.00 to 0.00 & -6.75 to 0.00 & \\
\hline \multicolumn{4}{|l|}{ Spherical equivalent (D) } \\
\hline Mean $\pm S D$ & $-3.67 \pm 1.79$ & $-4.23 \pm 2.33$ & 0.004 \\
\hline Range & -8.88 to 0.00 & -12.13 to +2.25 & \\
\hline \multicolumn{4}{|l|}{ Pachymetry $(\mu \mathrm{m})$} \\
\hline Mean $\pm S D$ & $519.92 \pm 33.76$ & $522.28 \pm 31.08$ & 0.701 \\
\hline Range & 462 to 588 & 468 to 594 & \\
\hline \multicolumn{4}{|l|}{$K_{1}$ values $(\mathrm{D})$} \\
\hline Mean $\pm S D$ & $43.16 \pm 1.59$ & $43.60 \pm 1.63$ & 0.153 \\
\hline Range & 40.40 to 46.40 & 38.90 to 48.70 & \\
\hline \multicolumn{4}{|l|}{$K_{2}$ values $(\mathrm{D})$} \\
\hline Mean $\pm S D$ & $44.59 \pm 1.69$ & $44.90 \pm 2.69$ & 0.319 \\
\hline Range & 41.30 to 47.20 & 39.90 to 72.90 & \\
\hline
\end{tabular}

$S D$ standard deviation, $U D V A$ uncorrected distance visual acuity, $C D V A$ corrected distance visual acuity, $D$ diopter

12-month visit, $86 \%$ and $98 \%$ of eyes were within $\pm 0.50 \mathrm{D}$ and $\pm 1.00 \mathrm{D}$ of the intended target, respectively (Fig. 1-V). To meet the FDA's criteria for refractive predictability, a minimum 

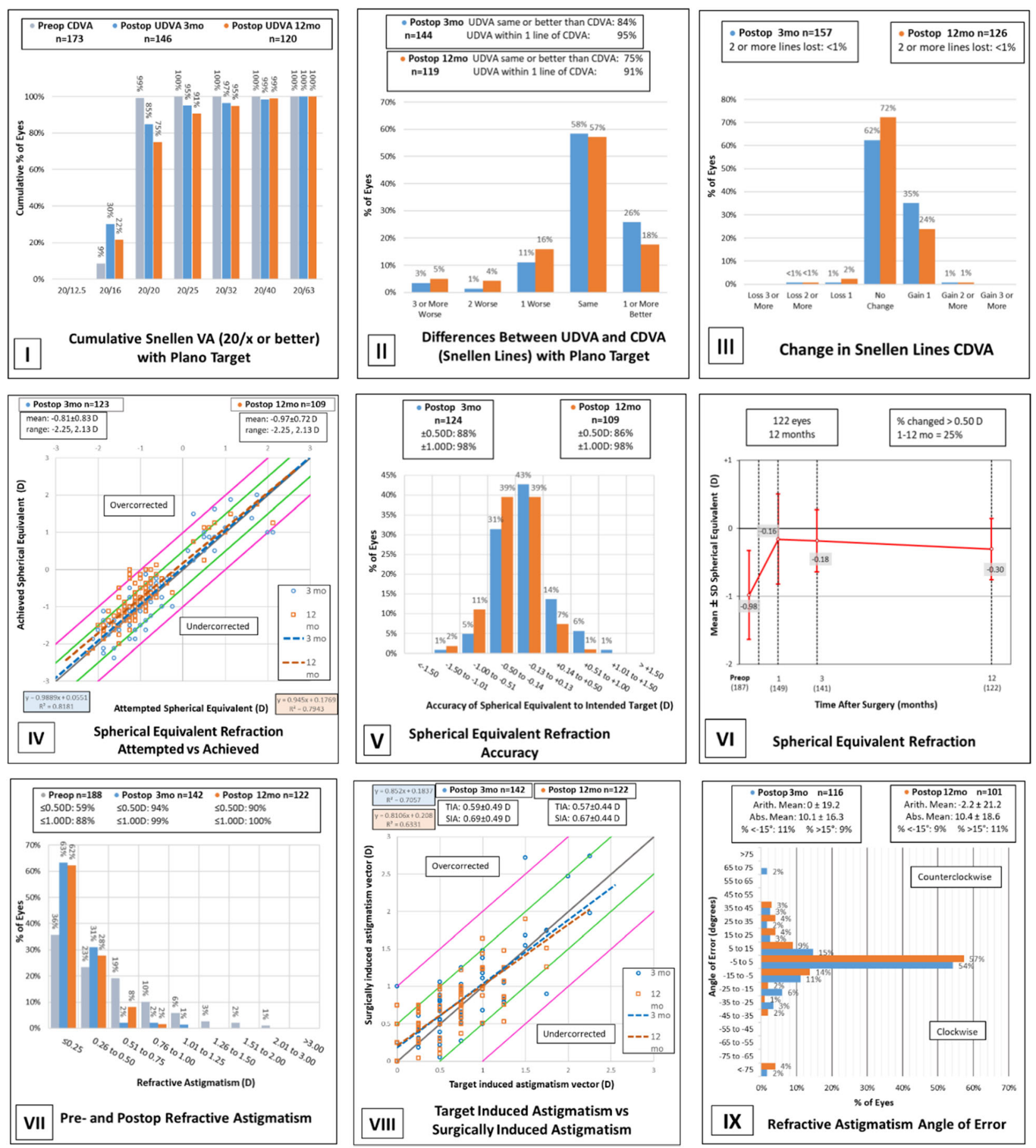

Fig. 1 Three-month and 12-month outcomes of wavefront-optimized PRK retreatment. I Cumulative Snellen VA $(20 / \times$ or better) with plano target. II Differences between UDVA and CDVA (Snellen lines) with plano target. III Change in snellen lines CDVA. IV Spherical equivalent refraction attempted vs achieved. V Spherical equivalent refraction accuracy. VI Spherical equivalent refraction. VII Pre- and postop refractive astigmatism. VIII Target induced astigmatism vs surgically induced astigmatism. IX Refractive astigmatism angle of error 
of $75 \%$ of eyes are required to achieve manifest refraction spherical equivalent (MRSE) within $\pm 1.00 \mathrm{D}$ of the intended outcome and at least $50 \%$ of eyes are required to achieve MRSE within $\pm 0.50 \mathrm{D}$ of the intended outcome at the point at which stability is first reached [16]. Our study exceeds this benchmark at both the 3-month and 12-month visits. Linear regression analysis showed a strong relationship between attempted and achieved SE, with the 3-month follow-up showing an $R^{2}$ value of 0.8181 and the 12-month follow-up showing 0.7943. At the 3-month and 12-month assessment, the absolute spherical equivalent overcorrection was 0.0551 and 0.1769 , respectively (Fig. 1-IV).

\section{Refractive Astigmatism}

Prior to enhancement, $59 \%$ of eyes had an astigmatism of at most $0.50 \mathrm{D}$ and $88 \%$ at most $1.00 \mathrm{D}$ (Fig. 1-VII). At the 3-month post-ENH visit, $94 \%$ and $99 \%$ of eyes had an astigmatism of at most $0.50 \mathrm{D}$ and at most $1.00 \mathrm{D}$, respectively, and after 12 months, $90 \%$ and $100 \%$ of eyes had an astigmatism of at most $0.50 \mathrm{D}$ and at most $1.00 \mathrm{D}$, respectively (Fig. 1-VII). The angle of error arithmetic mean and absolute mean were found to be $0 \pm 19.2^{\circ}$ and $10.1 \pm 16.3^{\circ}$, respectively, 3 months after ENH. The 12-month assessment showed an angle of error arithmetic mean of $-2.2 \pm 21.2^{\circ}$ and an absolute mean of $10.4 \pm 18.6^{\circ}$ (Fig. 1-IX). The 3-month post-enhancement follow-up showed mean TIA of $0.59 \pm 0.49 \mathrm{D}$ and mean SIA of $0.69 \pm 0.49 \mathrm{D}$, with an $R^{2}$ value of 0.7057 . The 12-month visit following retreatment showed a mean TIA and SIA of $0.57 \pm 0.44 \mathrm{D}$ and $0.67 \pm 0.44 \mathrm{D}$, respectively $\left(R^{2}=0.6331\right)$. The absolute overcorrection of the astigmatism vector was $0.1837 \mathrm{D}$ at 3 months after ENH and $0.208 \mathrm{D}$ at 12 months after ENH (Fig. 1-VIII).

\section{DISCUSSION}

Studies on PRK enhancement after primary PRK have been limited within the last few decades, with most studies done between 1996 and 2002 $[8-12,17]$. The number of eyes in these studies ranged from 51 to 90 in the initial part of the study; however, attrition rates were high. The percentage of eyes with a 1-year post-enhancement UDVA that was $20 / 20$ or better ranged from $26 \%$ to $39 \%$, while $64-86 \%$ had a 12-month UDVA of $20 / 40$ or better [8-12, 17]. Residual refraction at 1 year was within $\pm 1.00 \mathrm{D}$ of target in $50-88 \%$ of eyes [8-12, 17].

When compared to the studies published between 1996 and 2002, our results showed a larger improvement in most of the parameters analyzed with our study showing $75 \%$ of eyes with a UDVA of $20 / 20$ or better and $99 \%$ of eyes with a UDVA of 20/40 or better at the 12-month visit. When observing the residual refraction, $98 \%$ of eyes were within $\pm 1.00 \mathrm{D}$ of the intended target at 12 months.

Only three articles in the past 2 decades discuss PRK enhancement after primary PRK, with two of them having a sample size of less than four eyes [18-20]. Our results were most comparable to the study done by Broderick et al. [18], yet their study had a much higher percentage of male patients at 74\% likely because it was conducted at Walter Reed Army Medical Center. The study also had a smaller cohort of 78 eyes [18]. The authors reported a post-enhancement UDVA of at least $20 / 20$ in $69 \%$ of eyes at the 3-month visit and $71 \%$ of eyes at the 6-month visit while maintaining a CDVA within \pm 1 line of the pre-enhancement visit in $96 \%$ of eyes at 3 months and $100 \%$ of eyes at 6 months.

Given that the group of patients who eventually required an enhancement had a statistically significant higher degree of myopia and astigmatism than the control group, it can be postulated that these two characteristics are risk factors for the need for enhancement. The enhancement group did not have a statistically significant difference in age at the time of primary refractive surgery when compared to the control group. Patients with a higher degree of myopia are more likely to require PRK enhancement after primary PRK [21]. One large study reported that women undergoing refractive surgery were more myopic, on average, than men [22]. Women are also found to have increased rates of dry eye after refractive 
surgery, which could lead to epithelial hyperplasia and a myopic shift; however, studies for this complication are insufficient [23]. As female patients and those with a higher degree of myopia or astigmatism tend to undergo PRK enhancement following PRK at a higher rate, surgeons may wish to counsel these patients on their increased risk for requiring a second procedure during the preoperative discussion.

Our results showed better retreatment stability at both the 3-month and 12-month postenhancement visits when compared to other studies (Table 2). One of the limitations of our study was the loss of patients to follow-up with 29 eyes at the 3-month visit and then an additional 32 eyes at the 12-month visit.
Nevertheless, our study includes the largest sample size of patients undergoing PRK enhancement after primary PRK ever reported. Other limitations included the non-randomized retrospective nature of the study. The study also largely consisted of myopic eyes with very few being hyperopic. Given the lack of a large hyperopic sample size, it can be concluded that our results are more applicable to myopic eyes. Additionally, patients with residual refractive error and patients who were unsatisfied with their primary PRK also underwent PRK enhancement and were included in the study despite having a UDVA of 20/20 or better at the time of enhancement.

Table 2 Comparison of different studies assessing visual outcomes in patients with PRK enhancement after primary PRK surgery

\begin{tabular}{|c|c|c|c|c|c|c|c|c|}
\hline Study & Year & $\begin{array}{l}\text { No. } \\
\text { eyes }\end{array}$ & $\begin{array}{l}\text { Follow- } \\
\text { up } \\
\text { (months) }\end{array}$ & $\begin{array}{l}\text { UDVA } \\
20 / 20 \text { or } \\
\text { better }^{\mathrm{a}}\end{array}$ & $\begin{array}{l}\text { UDVA } \\
20 / 40 \text { or } \\
\text { better }^{\mathrm{a}}\end{array}$ & $\begin{array}{l}\text { CDVA loss } \\
\text { of } \geq 1 \\
\text { line }^{\mathrm{a}}\end{array}$ & $\begin{array}{l}\text { MRSE } \\
\text { within } \pm 0.50 \mathrm{D} \\
\text { of intended }^{\mathrm{a}}\end{array}$ & $\begin{array}{l}\text { MRSE } \\
\text { within } \pm 1.00 \mathrm{D} \\
\text { of intended }^{\mathrm{a}}\end{array}$ \\
\hline \multirow{3}{*}{$\begin{array}{c}\text { Snibson } \\
{[11]}\end{array}$} & \multirow[t]{3}{*}{1996} & \multirow[t]{3}{*}{58} & 3 & - & 27 & - & - & - \\
\hline & & & 6 & - & 22 & - & - & - \\
\hline & & & 12 & - & 64 & - & - & 69 \\
\hline \multirow[t]{2}{*}{ Pop [12] } & \multirow[t]{2}{*}{1996} & \multirow[t]{2}{*}{90} & 6 & - & 93 & 9 & - & - \\
\hline & & & 12 & - & 84 & - & - & 50 \\
\hline Hefetz [9] & 1997 & 66 & 12 & - & $\begin{array}{l}58.8^{\mathrm{b}} \\
\quad \text { (moderate } \\
\text { myopes) }\end{array}$ & - & - & $\begin{array}{l}88.2 \text { (moderate } \\
\text { myopes) }\end{array}$ \\
\hline $\begin{array}{c}\text { Rozsíval } \\
{[10]}\end{array}$ & 1998 & 48 & 6 & 26.1 & 82.6 & 23.6 & 45.8 & 75.0 \\
\hline Xia [19] & 1999 & 51 & 12 & 39.1 & - & - & - & 86.3 \\
\hline Pietilä [8] & 2002 & 63 & 12 & 38 & 86 & - & 64 & $\begin{array}{l}86 \text { (low residual } \\
\text { myopia) }\end{array}$ \\
\hline \multirow{2}{*}{$\begin{array}{l}\text { Broderick } \\
\quad[18]\end{array}$} & \multirow[t]{2}{*}{2016} & \multirow[t]{2}{*}{78} & 3 & 71.1 & - & - & 76.9 & - \\
\hline & & & 6 & 73.0 & - & - & 76.7 & - \\
\hline \multirow{2}{*}{$\begin{array}{l}\text { Current } \\
\text { study }\end{array}$} & \multirow[t]{2}{*}{2020} & \multirow[t]{2}{*}{188} & 3 & 85 & 99 & 7 & 88 & 98 \\
\hline & & & 12 & 75 & 99 & 9 & 86 & 98 \\
\hline
\end{tabular}

UDVA uncorrected distance visual acuity, CDVA corrected distance visual acuity, MRSE mean refractive spherical equivalent

a Values reported as percentage of eyes

b UDVA $20 / 25$ or better 
It should also be noted that none of the excimer laser platforms are FDA approved for use in enhancements after primary PRK or LASIK; therefore surgeons must discuss off-label usage with patients [14-16, 24]. While careful patient selection and thorough patient counseling are paramount, the present study as well as review of the literature indicate that PRK enhancement after PRK meets or exceeds the FDA criteria for safety, efficacy, and refractive predictability (Table 3). The efficacy endpoint consisting of $85 \%$ of eyes being $20 / 40$ or better is met by all of the studies published after 2002, with Snibson [11], Pop [12], and Rozsíval [10] being the only studies not meeting the criteria (Fig. 2). The clinical safety point of no more than $5 \%$ of eyes with a loss of two or more Snellen lines is met by most of the studies, with Rozsíval [10] being the only exception at 5.9\% (Fig. 3). The refractive predictability benchmark

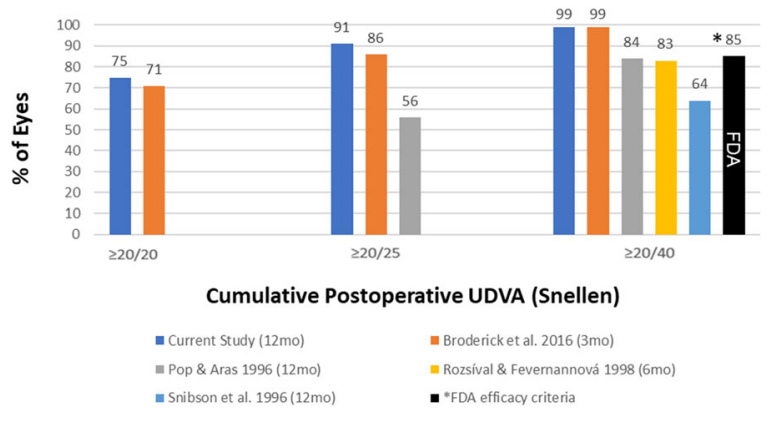

Fig. 2 Cumulative UDVA reported in the literature and FDA clinical efficacy endpoint

requires a minimum of $50 \%$ of eyes to achieve MRSE within $\pm 0.50 \mathrm{D}$ and $75 \%$ of eyes to achieve MRSE within $\pm 1.00 \mathrm{D}$ of the intended outcome which is met by Pietilä [8]. Broderick [18] did not examine the MRSE within $\pm 1.00 \mathrm{D}$ of the intended outcome but exceeded the benchmark at both the 3-month and 6-month

Table 3 FDA guidelines for the approval of excimer lasers

\begin{tabular}{|c|c|c|c|c|}
\hline & \multirow[t]{2}{*}{ Clinical endpoint } & \multirow{2}{*}{$\begin{array}{l}\text { FDA } \\
\text { criteria } \\
(\%)\end{array}$} & \multicolumn{2}{|c|}{ Current study } \\
\hline & & & $\begin{array}{l}3 \text { months } \\
\text { post-ENH } \\
(\%)\end{array}$ & $\begin{array}{l}12 \text { months } \\
\text { post-ENH } \\
(\%)\end{array}$ \\
\hline \multirow[t]{4}{*}{ Safety } & $\%$ of treated eyes with each ocular SAE type & $<1$ & 0.6 & 0.8 \\
\hline & $\%$ of eyes with loss of $\geq 2$ lines of CDVA & $<5$ & 0.6 & 0.8 \\
\hline & $\begin{array}{l}\% \text { of eyes with preoperative CDVA of } 20 / 20 \text { or better with a } \\
\text { postoperative CDVA worse than } 20 / 40\end{array}$ & $<1$ & 0.6 & 0 \\
\hline & $\begin{array}{l}\% \text { of eyes with }>2.00 \mathrm{D} \text { of induced MRC at refractive } \\
\text { stability compared to baseline }\end{array}$ & $<5$ & 0 & 0 \\
\hline Stability & $\begin{array}{l}\% \text { of eyes with a change of } \leq 1.00 \mathrm{D} \text { in MRSE and MRC } \\
\text { between } 2 \text { refractions, performed at } 1 \text { and } 3 \text { months } \\
\text { postoperatively, or over a } \geq 3 \text {-month period thereafter }\end{array}$ & $\geq 95$ & 96 & 98 \\
\hline Efficacy & $\begin{array}{l}\% \text { of eyes achieving UDVA of } 20 / 40 \text { or better for eyes with } \\
\text { CDVA of } 20 / 20 \text { or better preoperatively }\end{array}$ & $\geq 85$ & 99 & 99 \\
\hline \multirow[t]{2}{*}{ Predictability } & $\begin{array}{l}\% \text { of eyes achieving MRSE within } \pm 0.50 \mathrm{D} \text { of the intended } \\
\text { outcome }\end{array}$ & $\geq 50$ & 88 & 86 \\
\hline & $\begin{array}{l}\% \text { of eyes achieving MRSE within } \pm 1.00 \mathrm{D} \text { of the intended } \\
\text { outcome }\end{array}$ & $\geq 75$ & 98 & 98 \\
\hline
\end{tabular}

$E N H$ enhancement, $U D V A$ uncorrected distance visual acuity, $C D V A$ corrected distance visual acuity, $S A E$ serious adverse events, $M R C$ manifest refractive cylinder, $M R S E$ manifest refraction spherical equivalent, $D$ diopter 


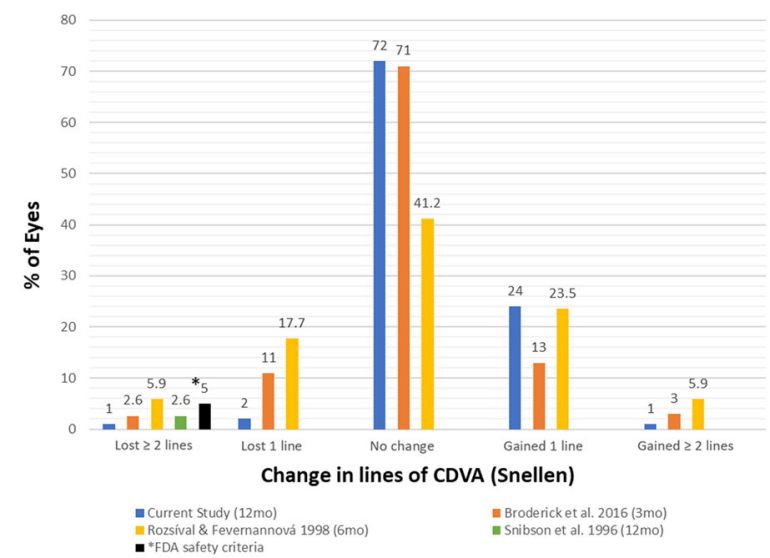

Fig. 3 Change in pre-enhancement to post-enhancement CDVA reported in the literature and FDA clinical safety endpoint

marks for the criteria of MRSE within $\pm 0.50 \mathrm{D}$. If further studies continue to demonstrate favorable results, perhaps expansion of excimer platforms' FDA indications for use to include retreatment after PRK could be considered.

\section{CONCLUSION}

Our study establishes the effectiveness, predictability, and safety of PRK retreatments following primary PRK meeting or exceeding the FDA criteria. Improvements are notable in most measured parameters after comparison of our study with the literature. Given the lack of discussion of PRK after PRK outcomes in the recent literature, we hope our results provide a precedent that will allow fellow clinicians to confidently manage post-PRK refractive surgery patients requiring retreatments.

\section{ACKNOWLEDGEMENTS}

Funding. This study was funded by an unrestricted grant from Research to Prevent Blindness (RPB), 360 Lexington Avenue, 22nd Floor New York, NY 10017. No support was received for the publication of this article.
Authorship. All named authors meet the International Committee of Medical Journal Editors (ICMJE) criteria for authorship for this article, take responsibility for the integrity of the work as a whole, and have given their approval for this version to be published.

Disclosures. Majid Moshirfar, Alex Villarreal, Andrew C. Thomson, William B. West Jr., Shannon E. McCabe, Eduardo Quinonez Zanabria, Derrick B. Graham, Yasmyne C. Ronquillo, and Phillip C. Hoopes Sr. declare that they have no conflict of interest.

Compliance with Ethics Guidelines. The study was approved by the Hoopes Vision Research Review-Board and BRANY Institutional Review Board. The study was also performed in accordance with the Helsinki Declaration and its later amendments. All patients were fully informed and consented to participate in the study. We sincerely thank the participants of this study.

Data Availability. The datasets generated and analyzed during the current study are available from the corresponding author on reasonable request.

Open Access. This article is licensed under a Creative Commons Attribution-NonCommercial 4.0 International License, which permits any non-commercial use, sharing, adaptation, distribution and reproduction in any medium or format, as long as you give appropriate credit to the original author(s) and the source, provide a link to the Creative Commons licence, and indicate if changes were made. The images or other third party material in this article are included in the article's Creative Commons licence, unless indicated otherwise in a credit line to the material. If material is not included in the article's Creative Commons licence and your intended use is not permitted by statutory regulation or exceeds the permitted use, you will need to obtain permission directly from the copyright holder. To view a copy of this licence, visit http://creativecommons.org/licenses/by$\mathrm{nc} / 4.0 /$. 


\section{REFERENCES}

1. Bourne RRA, Flaxman SR, Braithwaite $\mathrm{T}$, et al. Magnitude, temporal trends, and projections of the global prevalence of blindness and distance and near vision impairment: a systematic review and meta-analysis. Lancet Glob Health. 2017;5(9): e888-97.

2. Kim T, del Barrio JLA, Wilkins M, Cochener B, Ang M. Refractive surgery. Lancet. 2019;393:2085-98.

3. Chen LY, Manche EE. Comparison of femtosecond and excimer laser platforms available for corneal refractive surgery. Curr Opin Ophthalmol. 2016;27: 316-22.

4. Reinstein DZ, Archer TJ, Gobbe M. The history of LASIK. J Refract Surg. 2012; 28:291-8.

5. Shortt AJ, Allan BDS, Evans JR. Laser-assisted in-situ keratomileusis (LASIK) versus photorefractive keratectomy (PRK) for myopia. Cochrane Database Syst Rev. 2013;(1):CD005135. https://doi.org/10.1002/ 14651858.CD005135.pub3.

6. Stein R. Photorefractive keratectomy. Int Ophthalmol Clin. 2000;40:35-56.

7. Park S, Chuck RS. Corneal collagen cross-linking for correction of low myopia? Curr Opin Ophthalmol. $2013 ; 24: 273-4$.

8. Pietilä J, Mäkinen P, Uusitalo H. Repeated photorefractive keratectomy for undercorrection and regression. J Refract Surg. 2002;18(2):155-61.

9. Hefetz L, Krakowski D, Haviv D, Eshkoly M, Nemet P. Results of a repeated excimer laser photorefractive keratectomy for myopia. Ophthalmic Surg Lasers. 1997;28(1):8-13.

10. Rozsíval P, Feuermannová A. Retreatment after photorefractive keratectomy for low myopia. Ophthalmology. 1998;105(7):1189-93.

11. Snibson GR, McCarty CA, Aldred GF, Levin S, Taylor HR. Retreatment after excimer laser photorefractive keratectomy. Am J Ophthalmol. 1996;121(3):250-7.

12. Pop M, Aras M. Photorefractive keratectomy retreatments for regression: one-year follow-up. Ophthalmology. 1996;103(11):1979-84.
13. Waring GO, Reinstein DZ, Dupps WJ, et al. Standardized graphs and terms for refractive surgery results. J Refract Surg. 2011;27:7-9.

14. FDA. Summary of safety and effectiveness data. http://www.accessdata.fda.gov/cdrh_docs/pdf/ P970053b.pdf. Accessed 26 Aug 2020.

15. FDA. P930016/S044: FDA Summary of Safety and Effectiveness Data 1. Summary of safety and effectiveness data (SSED).

16. FDA. PMA P020050/S12: FDA summary of safety and effectiveness data summary of safety and effectiveness data (SSED). http://www.accessdata. fda.gov/cdrh_docs/pdf2/P020050b.pdf. Accessed 10 Nov 2020.

17. Xia X, Liu S, Huang $P$, et al. [Retreatment after excimer laser photorefractive keratectomy]. Zhonghua Yan Ke Za Zhi. 1999;35(3):203-6.https:// pubmed.ncbi.nlm.nih.gov/11835807/. Accessed 8 Aug 2020.

18. Broderick KM, Sia RK, Ryan DS, et al. Wavefrontoptimized surface retreatments of refractive error following previous laser refractive surgery: a retrospective study. Eye Vis. 2016;3(3). https://doi.org/ 10.1186/s40662-016-0034-x.

19. Pöschl EM, El-Shabrawi Y, Ardjomand N. Central corneal haze after wedge resection following penetrating keratoplasty and photorefractive keratectomy. Eye (London, England). 2013;27(5):679-80.

20. Alio JL, Soria FA, Abbouda A, Peña-García P. Fifteen years follow-up of photorefractive keratectomy up to $10 \mathrm{D}$ of myopia: outcomes and analysis of the refractive regression. $\mathrm{Br} \mathrm{J}$ Ophthalmol. 2016;100(5): 626-32.

21. Naderi M, Sabour S, Khodakarim S, Daneshgar F. Studying the factors related to refractive error regression after PRK surgery. BMC Ophthalmol. https://doi.org/10.1186/s12886-018-0879-y.

22. Vainer I, Mimouni M, Rabina G, et al. Age- and gender-related characteristics of corneal refractive parameters in a large cohort study. Am J Ophthalmol. 2020;209:45-54.

23. Shehadeh-Mashor R, Mimouni M, Shapira Y, Sela T, Munzer G, Kaiserman I. Risk factors for dry eye after refractive surgery. Cornea. 2019;38(12):1495-9.

24. FDA. Premarket Approval (PMA). https://www. accessdata.fda.gov/scripts/cdrh/cfdocs/cfpma/pma. cfm?id=P020050. Accessed 26 Aug 2020. 